\title{
Comparison Of Conjunctival Autograft And Combined Amniotic Membrane Mini-Simple Limbal Epithelial Transplantion After Primary Pterygium Excision
}

ASHOK JHA ( $\square$ ashokjha1025@gmail.com )

MILITARY HOSPITAL GAYA https://orcid.org/0000-0001-7072-4168

Abhay Simba

AN Magadh Medical College and Hospital

Research article

Keywords:

Posted Date: September 15th, 2020

DOI: https://doi.org/10.21203/rs.3.rs-30962/v2

License: (a) (i) This work is licensed under a Creative Commons Attribution 4.0 International License.

Read Full License 


\section{Abstract}

The authors have requested that this preprint be withdrawn due to author disagreement.

\section{Full Text}

The authors have withdrawn this preprint from Research Square. 